\title{
ДОКТРИНАЛЬНАЯ ДИСКУССИЯ О СООТНОШЕНИИ ПОНЯТИЙ «КОММЕРЧЕСКОЕ ПРЕДСТАВИТЕЛЬСТВО» И «КОММЕРЧЕСКОЕ ПОСРЕДНИЧЕСТВО»
}

\author{
(C) 2020 Хугаева Дзерасса Ильдеровна \\ аспирантка кафедры коммерческого права и основ правоведения \\ Московский государственный университет имени М. В. Ломоносова, Россия, Москва \\ E-mail:kdzerassa@bk.ru
}

В рамках этой исследовательской работы был проведен всесторонний анализ доктрин, различных мнений и точек зрения по вопросу сравнения и взаимоотношений таких понятий, как коммерческий посредник и коммерческий представитель; доктринальные противоречия сопоставления коммерческого посредничества и коммерческого представительства.

Ключевые слова: коммерческое представительство и посредничество, торговое посредничество, проведение коммерческих операций, договорные взаимоотношения сторон.

Актуальность этого исследования определяется теоретическим смыслом и практической значимостью таких социально-экономических феноменов, как коммерческое посредничество и коммерческое представительство. Эти формы торговой деятельности активно реализуются в современных условия развития российского общества, а также на международном уровне. Однако с правовой точки зрения сегодня отсутствует четкое понимание сущности институтов по воздействию их на торговые отношения в рамках национальной экономики в Российской Федерации. Существует несколько базовых определений понятий коммерческое представительство и коммерческое посредничество. Выделим и рассмотрим каждое из них более подробно.

С другой стороны, важно отметить, что в развитых государствах данные правовые институты четко разграничиваются, научное сообщество Европы и США относится их к разным отраслям права, что закреплено на общем уровне законодательства. Это может быть обусловлено противоречиями применения и реализации целей и задач рассматриваемых правовых институтов. Чтобы так или иначе устранить эти пробелы, необходимо создание теоретической базы и эффективное законодательное закрепление этих социальных явлений.

В соответствии с утверждением из словаря русского языка за авторством С.И. Ожегова, под коммерцией принято понимать торговые отношения и ряд операций, связанных с получением прибыли за реализацию товаров и услуг, а значит термин «коммерческих» сопоставим с «торговым», а коммерсант - это такой человек, которые участвует в торговых процессах. Далее необходимо рассмотреть понятия посредничества и представительства.

Посредничество является уникальным процессом содействия субъектам по договоренности или при заключении сделки с четкими требованиями для каждой из сторон. Таким образом, посредник - это физическое лицо, фирма и организация с должностными лицами, которые принимают непосредственное участие в переговорах между сторонами для достижения диалога, по итогам которого можно прийти к реализации поставленной цели.

Под представительством понимается исполнение определенным правил и обязанностей представителя, так же физического лица или организации, как и в случае с посредничеством, когда представитель отражает потребности или интересы конкретного субъекта; это специфическое право выбора обращения за помощью через третье лицо. Получается, что представителем является тот, кто сообщает потребности, интересы или позицию представляемого субъекта в заключении договора, в торговых отношениях и так далее [8, с. 264; с. 522; с. 534].

Отметим также, что коммерция, как термин, сформировалась в переводе с латыни, и первоначально имело значение торговли. В свою очередь торговля - это общепризнанная деятельность, вид взаимоотношений людей и обществ с древних времен; он представляет собой процесс приобретения и сбыта услуг или товаров, независимо от их цены, назначения, качества, ко- 
личества и иных признаков. В широком смысле слова - это процесс купли-продажи с отличием этого вида деятельности, сопутствующими договоренностями сторон, а также необходимость организации проведения торговых операций или финансовых, платежных операций. Коммерция включает в себя множество фактов, итогов торговой деятельности, процессов и операций купли-продажи.

В современных условиях развития рыночных отношений коммерческую деятельность может выполнять посредник, наделенный соответствующими в этой сфере полномочиями. В английском языке представлено большое число терминов в сфере рыночных отношений, так, например, только к обозначению посредника в торговли подходят «agent, conciliator или mediator». Последнее является наиболее подходящим из-за особенностей перевода на русский язык.

Как уже было сказано, посредником может выступать как организация, так и частное лицо, контактирующее с другими субъектами коммерции либо торговых процессов и реализующее договорные обязательства, определенные задачи и функции взаимодействия этих субъектов для обеспечения процесса купли-продажа в отношении установленных товаров либо услуг. В коммерции контрагентами чаще всего являются производители товаров или частые лица, которые представляют этот бренд, а также это могут быть потребители, как с заключением оптовых, так и розничных торговых договоренностей.

На сегодняшний день самым спорным вопросом остается определение и толкование понятия коммерческо-посреднической деятельности. По мнению отечественных и зарубежных специалистов в данной сфере, посредничество в коммерции представляет собой сложную, многогранную операцию либо, что в большинстве случаев учитывается научным сообществом, организационную оперативную систему, целью которой является обеспечение торговых связей и процессов, направленных при этом на успешное взаимодействие, то есть, что и является целью коммерции - получение максимальной прибыли или выгоды для стороны, приобретающей конкретный товар или услугу.

В современной реальности торговых отношений участие посредников в коммерческой деятельности является весьма актуальным, в том числе и в РФ. Хоть в настоящее время в госу- дарстве отмечается кризис экономики, а также нестабильность рыночных отношений, одновременно с этим продолжаются процессы развития оптовой, розничной и мелкооптовой торговли, где могут быть реализованы возможности коммерческого посредничества. Теория этого посредничества во многом базируется на деятельности посредника.

В данном случае посредник - это человек, наделенными определенными навыками и знаниями в коммерческой деятельности, знающий основы работы в торговле, содержание процессов купли-продажи, деловой коммуникации и иных важных аспектов. Также к преимуществам коммерческого посредника в современных условиях относятся умение заключать взаимовыгодные сделки, разбираться в многообразии вкусов клиентов, прогнозировать их интересы и результаты торговых процессов, платежных операций.

Что же касается коммерческого представительства, то оно отличается от посредничества по многим параметрам. В первую очередь тем фактом, что это представительство является объектом рассмотрения гражданского права. Тем самым, коммерческое представительство это процесс заключения от имени другого лица представителем коммерческих соглашений и договора купли-продажи, как наиболее распространенного вида договорных обязательств при торговой деятельности.

В последнее время было проведено множество исследования сравнения содержаний коммерческого посредничества и коммерческого представителя, причем особое внимание уделялось сущности этих двух понятий, отличиям их друг от друга, как в теории, так и в практической реализации. Так, например, в работах ученыхэкономистов прослеживается тенденция к анализу проблем хозяйственного контроля и управления коммерческого посредничества, и при этом рассматривается связь этого правового является с представительством в коммерческой деятельности. Большинство исследований по этому вопросу так или иначе проводятся юристами и правоведами.

Дискуссионным остается вопрос соотношения работы коммерческого и торгового представителя с работой коммерческого посредника. Разные ученые придерживаются противоположных точек зрения. Интересна позиция юриста А.Первомайского, по мнению которого, это 
два абсолютно независимы по своей сущности факта в торговой деятельности и каждый из них применяется в конкретных ситуациях [10, с. 1].

С точки зрения российского ученого В.А.Васильевой коммерческого и торговое представительство являются независимым правовым институтом, и так же, как и посредничество может быть реализована, в рамках помощи для предпринимателей, участников торговых процессов. Но в то же время формат посредничества имеет сложную структуру, что выгодно отличает его от ранее используемой формы представительства [1, с. 37]. Р. О. Короткова считает, что в коммерческое посредничество входят компоненты представительства [7, с. 82]. При этом И.Н.Галушина рассматривает разграничение этих юридических фактов в зависимости от реализации интересов третьей стороны, перечня их целей и задач такого взаимодействия [2, с. 124]. А.И.Дришлюк акцентирует внимание на агентском представительстве [4, с. 85], и как мы видим эта форма, выраженная в посредничестве, не относится законодательно к торговому или коммерческому представительству [6, с. 216; 5, с. 15; 13, с. 439].

Также интересна позиция доктора юридических наук, Б.И.Пугинского, по мнению которого, коммерческое посредничество и в то же время отличное от него коммерческое представительство имеют схожую особенность, которая выражена в одностороннем характере этих двух процессов выполнения весьма различных профессиональных задач в торговой деятельности. Так, например, для коммерческого посредничества характерно наличие элементов и средств представительства, при том, что представительство само по себе не связано с коммерческим посредничеством [11, с. 216].

Для С.А. Спиридонова коммерческое посредничество является особым комплексным правовым институтом, сочетающим в себе особенности формы посреднической деятельности и представительства [14, с. 47]. Автор этой исследовательской позиции поддерживает эту точку зрения, считая ее верной и логически выстроенной, без акцента на незначительные, дополни- тельные черты того или иного вида коммерческой деятельности с участием третьих лиц.

Таким образом, существуют три группы определения и соотношения в рассмотрении двух правовых институтов коммерческого представительства и коммерческого посредничества. В.В.Резников относит к первой категории те определения, которые признают трансформацию представительства на особом этапе развития, становясь посредничеством. Ко второй категории убеждений принято относить позиции ученых, что посредничество в узком смысле слова представляет собой простое посредничество, а в широком смысле слова - это еще и представительство. К третьей категории относят суждения, которые в большей мере рассматривают коммерческое посредничество в узком смысле, без увязки с представительством [12, с. 73].

Коммерческое посредничество может видоизменяется и достигать форм представительства в предпринимательской деятельности по той причине, что посредник выполняет одновременно функции представитель-посредник [3, с. $15 ; 9$, с. 20]. Также стоит отметить, что в англо-саксонской правовой системе представительство подконтрольно положениям прецедентного права и актам судебных инстанций. Представительство в континентальном праве оценено в более широком смысле, без разделения на договорное и законное [15, с. 94].

В ГК РФ ст. 184 посвящена коммерческому представительству. Но о коммерческом посредничестве в российском законодательстве есть только краткие упоминания. На основании всего вышесказанного мы рассматривает понятия коммерческое представительство и коммерческое посредничества и исходим из современных условий, при которых отсутствует в науке единый подход к толкованию этих правовых явлений, как в отношении содержаний, так и соотношения представительства и посредничества в разных формах и видах предпринимательской деятельности. Требуется детальное изучение этой темы, с теоретической и практической точек зрения.

\section{Библиографический список}

1. Васильева В.А. Проблемы гражданско -правового регулирования отношений, связанных с предоставлением посреднических услуг. Автореферат докт. дис... / В.А. Васильева.-Киев. - 2003. - 37 с.

2. Галушина И.Н. Посредничество в гражданском и торговом законодательстве Франции и Германии / И. Н. Галушина // Закон. - 2005.- № 2-122-124 с. 
3. Гришин С. М. Коммерческое представительство и посредничество в правопорядках Российской Федерации и стран континентальной Европы. Дис.канд.юрид.наук/ С. М. Гришин - М. - 2011. - 162 с.

4. Гражданское право. Под ред. Ю. К. Толстого, А. П. Сергеева.-М., 2016.

5. Гришиаев С.П.Гражданское право.-М., 2017.

6. Гаврилов Э. Когда заказчик становится собственником предмета договора подряда? //Российская юстиция., 2016. № 11.

7. Калпин А.Г., Масляев А. И. Гражданское право.- М., 2015.

8. Протас Е. В. Договор поставки в условиях рыночной экономики: Учебное пособие,- М.: МГИУ, 2018.

9. Ожегов С.И. Словарь русского языка.-М.: Русский язык, 1977.- 846 с.

10. Завидов Б. Общие положения о подряде// Российская юстиция. 2015. - № 11

11. Завидов Б. Д., Гусев О.Б. «Особые условия» договора как специфический раздел контракта и как одно из условий ответственности его контрагентов //.Право и экономика, 2018. № 10.

12. Пугинский Б. И. Коммерческое право России: учебник / Б. И. Пугинский. - 2-е изд. - М.: Зерцало, 2007. - 350 c.

13. Сафиуллина Г.Д. Предмет агентского договора и основные идеи представительства (действие «в чужих интересах» и действие «от чужого имени»): сравнительно-правовой аспект / Г. Д. Сафиуллина // Цивилистические записки: меж вуз. сб. науч. трудов.- М.: Статут; Екатеринбург: Ин-т частного права.-2015.- Вып. 4. - 439-447 c.

14. Спиридонов С. А. Посредничество как комплексный институт гражданского права РФ. Дис.канд. юрид. наук/ С. А. Спиридонов. - Москва. - 2017.- 143 с.

15. Эрделевский А. М. Общие положения о подряде -Подготовлен для Системы КонсультантПлюс, 2017. 